\title{
Awareness and Self Perceived Effect of Noise Pollution among Students of Tertiary Institutions in Ilesa, South-Western Nigeria
}

\author{
Article by Akinyemi Patrick Ayodeji, Ojo Temitope Olumuyiwa. \\ Department of Community Health, \\ Obafemi Awolowo University Teaching Hospital Complex, \\ Ile-Ife, Osun State. Nigeria. \\ Email: kindepat@texilaconnect.com
}

\begin{abstract}
This research work was aimed at assessing the awareness and perceived effect of noise pollution among students of tertiary institution in Osun State. Questionnaire was administered to 125 respondents in this descriptive cross sectional study. The degree of exposure was assessed using three questions- intensity of noise relative to that of busy traffic; need to raise voice at the location and raising volume of music gadget after leaving the site. Knowledge of common effect noise was also assessed.

There was moderate level of awareness of effect of noise pollution among the participants, $58.4 \%$ of the respondents. The common sources of noise pollution were peoples' conversation, generator and traffic congestion. Despite this level of awareness of noise pollution, awareness of existence of noise regulatory law is very low. Only 24\% of the respondents were aware of the law.
\end{abstract}

\section{Introduction}

Noise can be defined as a wrong sound in a wrong place at a wrong time (Park, 2009).

It is an undesirable sound which usually results from human activities; however, it may also be from natural cause.

Noise pollution takes place when there is either excessive amount of noise or an unpleasant sound that causes temporary disruption in the natural balance.("Understanding noise pollution,")Chronic exposure to noise above $85 \mathrm{~dB}$ for prolong period of time has being shown to be associated with sensori-nueral deafness(Park, 2009). From medical report of students attending a school for the handicapped in Lagos State, Nigeria, it was shown that $80 \%$ of the pupils were borne without hearing impairment. It was shown that most common causes of deafness were infections. This was followed by other causes like noise pollution.

Other effects of noise pollution include interference with communication, sleep disturbance, cardiovascular disturbance, disturbance of mental health, disturbance of cognitive task performance, undue aggression and other anti-social behaviour(Committee; Lisa \& Louis, 2007; "Understanding noise pollution,"). Noise pollution has been confirmed to be a biologic stressor which has been implicated as one of the risk factors of chronic non-communicable diseases cardiovascular diseases and has been implicated in activating latent mental illness(Aluko \& Nna, 2015; Lisa \& Louis, 2007; Park, 2009).

Despite these numerous adverse effect of exposure to noise pollution, the rate of pollution is increasing daily with development of human activities that contributes to noise generation. Among these activities are siting of religious centers (churches and mosque), club house and event center which is the order of the day in most cities in Nigeria without following the town planning codes for building such centers. These thus increase community noise pollution as most are sited close to residential area to enjoy good patronage.

Several studies have been conducted to assess the awareness and perceived effect of noise pollution among different group of people with mixed result.

In a study conducted by Shield and Dockrell (2003), among school children in London, they assessed the perceived effect of noise exposure in the classroom. It was revealed that the most widespread and well documented subjective response to noise is annoyance. Noise was also shown to 
South American Journal of Public Health

Special Edition May 2016

significantly affect school performance among the children. The children of older age group were discovered to be more affected in term of their performance(Shield \& Dockrell, 2003).

In a similar study conducted by Nermin Bulunuz (2014) among Turkish elementary school children, he assessed their awareness and sensitivity to noise pollution. It was discovered that both the school children and the teachers have low level of awareness of noise pollution. A pre and post training questionnaire was administered to assess the awareness and sensitivity of the teachers. It was discovered that approximately $25 \%$ of the students in both public and private schools said that the noise level in the school was normal or there was no noise. This percentage however reduced in posttraining test to $10 \%$ in public school while that of private school remain approximately the same as in pre-training test. In pre training test in both public and private schools, $70 \%$ of the students react to noise with annoyance. This increases to above $90 \%$ in both schools in post-training test. About $50 \%$ of the students in both schools said they were sometimes or never warned about noise pollution by their teachers while in post-training test, $76.3 \%$ of the public school students and $57.4 \%$ of the private school students told that they were "always" warned by their teachers when they made noise(Bulunuz, 2014).

A study was conducted by Farzana et al (2014) on noise pollution of a stone crusher machine at Jaflong in Sylhet, Bangladesh which assess perceived effect of noise pollution among various occupational groups. Among the student group containing 30 students, it was discovered that $93 \%$ students complained of headache, $95 \%$ student complained of sleep interference and $85 \%$ felt hearing deficiency. About $95 \%$ of students also suffer from irritation, $96 \%$ of them had undergone attention deficiency and $90 \%$ student said they have bad temperament if they are subjected to high level of sound. Concerning awareness of the health of noise pollution, $10 \%$ of the students were aware of the health effect, $78 \%$ were unaware and $12 \%$ were not sure(Farzana, Nuri, Biswas, \& Das, 2014).

In a similar study conducted among Ghanaian students resident in Hall of University of Cape Coast on perceived effect on noise pollution by Essandoh P.K. et al (2011), noise level in various hall of residence was assessed. Most of the students admitted that noise disturb their studies and sleep. There was however no significant association between hall of residence (base on the noise level) and level of irritation among the students $(\mathrm{P}-\mathrm{value}=0.180$, level of significance $=0.05)$. The common sources of noise in the hall of residence were argument, morale, music, prayer/preaching, cadets and hawkers(Essandoh, Armah, Afrifa, \& Pappoe, 2011).

In a local study conducted among social studies education students of a tertiary institutions in Enugu, Nigeria on awareness and safety measures of noise induced hearing loss by Onuigbo et al (2013), the findings of the study among others showed that the students in the 5 tertiary institutions in Enugu were not aware of the causes of NIDHL and their consequences(Onuigbo, Onuoha, \& Ugwuanyi, 2013).

A study conducted by Awosusi and Akindutire (2014) among people of Ado Ekiti Metropolis, Ekiti State Nigeria on perceived health effect of noise pollution, it was concluded that there is high level of awareness among the participants. Religious homes were not seen as source of noise as the mean score was 1.42 which was below acceptance level of 1.50 . Other sources like traffic, bar/club houses, construction work were above 1.50 thus accepted as sources of noise pollution. The mean scores of noise pollution could cause sleep disturbance, hearing impairment and stress/ anxiety were above 1.50. While, the mean score of the responses to the items that noise pollution can cardiovascular diseases headache and accidents were below 1.50. The mean score of noise reduces concentration, leads to headache, prevents me from sleeping and affects my health exceeded 1.50. There was also statistically significant association between awareness and level of education, also between location of participants and perception of health effect of noise pollution(Awosusi \& Akindutire, 2014).

Various studies in different regions of the world and among different classes of people have come out with varying result on awareness and perceived health effect of noise pollution. Based on these findings, this study is aimed to find out if the students of tertiary institution in Osun State are aware of noise pollution and their perceived health effect.

Students of tertiary institution belong to group of people that requires much concentration and attention to achieve their study objectives. Noise in the institutions of learning just like in the society 
at large is increasing due to students' activities and activities of other staffs of the community. This includes noise from equipment for business activities and social activities.

The requirement of serene environments for the major activities of this group of people makes them more prone to the effect of noise pollution hence this study among them.

\section{Methodology}

\section{Description of the study area}

This study was conducted in three tertiary institutions in Osun State, Nigeria $\left(7^{\circ} 30^{\prime} \mathrm{N} 4^{\circ} 30^{\prime} \mathrm{E}\right)$. The state has numerous tertiary institutions including private and public universities, polytechnic, colleges of education and health technology. The people of Osun State are mainly traders, artisan and farmers(Osun, 2014). They are predominantly Yoruba by tribe but accommodate people from various tribe because of trade, education, intermarriage and others. It occupies an area of 9,251 km2 sharing border with Ondo, Ekiti, and Oyo states(Osun, 2014).

\section{Study Population}

Students of College of Health Technology Ilesa, a tertiary institution who were willing were enrolled into the study. Participants involve all willing students irrespective of their level or department. Visiting students from other school were however excluded from the study.

\section{Study Design}

Descriptive cross sectional study

Sampling methods and sample size

The institution was selected based on proximity and ease of access to the student due to limited time available for the study. Students were randomly recruited irrespective of their department at informal settings within the school.

The size was determined using:

Where:

$$
\mathrm{n}=\mathrm{Z}^{2} \mathrm{pq} / \mathrm{d}^{2}
$$

$\mathrm{z}=$ standard normal deviate usually set at 1.96

$\mathrm{p}=$ proportion in the target population estimated to have certain characteristics

$\mathrm{q}=1-\mathrm{p}$

$\mathrm{d}=$ degree of freedom $=0.05$

$\mathrm{p}=$ prevalence of perceived health effect in a study conducted at Ibadan $=84 \%$ (Ana, Shendel, Brown, \& Sridar, 2009)

$$
\begin{gathered}
\mathrm{z}=1.96 \\
\mathrm{p}=84 \%=0.84 \\
\mathrm{q}=1-\mathrm{p}=0.16 \\
\mathrm{n}=\frac{1.96^{2} * 0.84 * 0.16}{0.05^{2}}
\end{gathered}
$$

$$
\mathrm{n}=206
$$

Leslie-fishers formula for population less than 10000

$\mathrm{Nf}=$ desired sample size when population is $<10000$

$\mathrm{n}=$ desired sample size when population is $>10000$

$\mathrm{N}=$ estimated population size (population of the school) $=311$

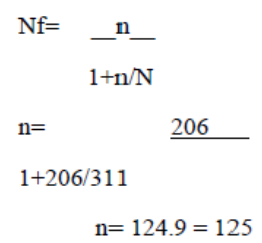


South American Journal of Public Health

Special Edition May 2016

\section{Study Tool}

A questionnaire was designed containing the socio-demographic variables, questions to elicit the awareness, perceived effect of noise pollution and common sources of noise pollution.

\section{Method of data collection}

Data was collected on the campus using close ended questionnaire. The students were met at convenient environment like hostel and relaxation spot to administer the questionnaire.

\section{Method of data analysis}

Data were analysed using computer software SPSS version 20 for windows. The data were analysed using univariate analysis. The degree of exposure was scored bases on three important questions; if the noise is louder than busy traffic, raising voice to talk to someone close by and if respondent do increase volume of TV or radio after leaving the source of noise. Knowledge of the effect was also scored by adding their score on each mentioned effectand compared with the mean score

\section{Ethical consideration}

Approval was obtained from the concerned authorities in the school. Informed consent was obtained from the participants before administration of questionnaire and data collected were kept in a pass worded laptop.

\section{Result}

A total number of 125 students were drawn from the tertiary institution involved in this study.

Table 1: Demographic Characteristics of the Respondents Values are given as n (\%)

\begin{tabular}{ll}
\hline Characteristics & Frequency N (\%) \\
\hline Age (years) & \\
20 and below & $27(21.6)$ \\
$21-25$ & $51(40.8)$ \\
26 and above & $47(37.6)$ \\
Sex & \\
Male & $69(56.1)$ \\
Female & $56(43.9)$ \\
Religion & \\
Christianity & $94(75.2)$ \\
Islam & $31(24.8)$ \\
\hline$* *$ mean age 24.38
\end{tabular}

Table 2: Characteristics of the exposed noise

\begin{tabular}{ll}
\hline Characteristics & Frequency N (\%) \\
\hline Perceived exposure to noise & \\
Yes & $111(88.8)$ \\
No & $14(11.2)$ \\
Frequency of exposure & \\
Daily & $78(62.4)$ \\
Alternate day & $21(16.8)$ \\
Weekly & $14(11.2)$ \\
Monthly & $3(2.4)$ \\
Missing & $9(7.2)$ \\
Location of exposure & \\
Hooting from traffic & $71(20.7)$ \\
Religious houses & $47(13.7)$ \\
Social event & $68(19.8)$
\end{tabular}




\begin{tabular}{ll} 
Place of work & $46(13.4)$ \\
Relaxation center & $49(14.3)$ \\
$\begin{array}{l}\text { Market } \\
\text { Sources of noise pollution }\end{array}$ & $62(18.1)$ \\
$\begin{array}{l}\text { Peoples conversation } \\
\text { Generator }\end{array}$ & $74(35.9)$ \\
Public address system & $49(23.8)$ \\
Factory engines & $31(15.0)$ \\
Hooting from cars & $23(11.2)$ \\
Noise exposure score & $29(14.1)$ \\
High exposure & \\
Low exposure & $81(64.8)$ \\
\hline
\end{tabular}

$88.8 \%$ of the respondents are aware of the exposure to noise with major location of exposure being in traffic congestion which account for $20.7 \%$. People's conversation either in form of quarrel or others is the commonest cause of noise pollution (35.9\%). This is followed by noise from generator accounting for $23.8 \%$ of causes.

The noisiest time in the neighbourhood of respondent was the afternoon (47.2\% of respondents) followed by night (27.2\%). 64.8\% of the respondents have high exposure to noise

Table 3: knowledge of effect of noise pollution and perceived effect of noise among the participants

\begin{tabular}{ll}
\hline Characteristics & Frequency N (\%) \\
\hline Noise have effects on man & \\
Yes & $112(91.1)$ \\
No & $11(8.9)$ \\
Knowledge of effect of noise & \\
Hearing impairment & $100(14.2)$ \\
Stress \&anxiety & $63(8.9)$ \\
Heart disease & $39(5.5)$ \\
Sleep disturbance & $103(14.6)$ \\
Headache & $108(15.3)$ \\
Annoyance & $82(11.6)$ \\
Accident & $59(8.4)$ \\
Poor academic performance & $76(10.8)$ \\
Decrease life span & $74(10.5)$ \\
Score for level of knowledge & \\
Good knowledge & $73(58.4)$ \\
Poor knowledge & $52(41.6)$ \\
\hline
\end{tabular}

Majority (58.4\%) are aware that noise has adverse effect on man. Majority are aware that noise can cause sleep disturbance and headache while only $5.5 \%$ of the respondents are aware that noise pollution is associated with heart diseases.

Table 4: Perceived effect of noise pollution by the respondents

\begin{tabular}{ll}
\hline Characteristics & Frequency N (\%) \\
\hline Difficulty with hearing & $78(17.3)$ \\
Undue aggression & $74(10.7)$ \\
Sleep disturbance & $91(20.2)$ \\
poor concentration & $82(18.2)$ \\
headache & $99(22.0)$ \\
\hline
\end{tabular}


South American Journal of Public Health

Special Edition May 2016

Table 5: Awareness of country law against noise pollution

\begin{tabular}{ll}
\hline Characteristics & Frequency N (\%) \\
\hline Awareness of law against noise pollution & \\
Yes & $30(24.0)$ \\
No & $95(76.0)$ \\
\hline
\end{tabular}

Majority of the respondents (76\%) are not aware of any legislation against community noise pollution.

\section{Discussion, conclusion and recommendation}

Majority of the respondents are aware of their regular exposure to noise. This is in contrast with the conclusion of Nermin Bulunuz(Bulunuz, 2014) and Onuigbo(Onuigbo, et al., 2013) who both concluded that their respondents have low level of awareness. The respondents in this study were students of tertiary institution and under training to be a medical workers. These could be responsible for the difference in the level of awareness as the study by Nermin Bulunuz was conducted among students of elementary school and study by Onuigbo was conducted among students of tertiary institution in non-medical related fields. Similar to the findings of Awosusi A. et al, the common sources of noise pollution werepeople's conversation, generator, and relaxation centers like club house. Though religious house was also not a significant source of noise pollution to the respondents, it contributes more as a source of noise pollution compared with the findings of Awosusi(Awosusi \& Akindutire, 2014).

The most common perceived effects were headache and sleep disturbance, this is similar to the findings of Farzana, Essandoh and Awosusi(Awosusi \& Akindutire, 2014; Essandoh, et al., 2011; Farzana, et al., 2014) however headache was below the mean score in the study by Awosusi. Poor concentration on their study is also a big challenge as $82(18.2 \%)$ of the respondent indicate that it disturbs their concentration similar to the findings of Essandoh among Ghanaian tertiary institution students(Essandoh, et al., 2011). The study was conducted in a tertiary institution which requires serene environment to cope with their academic work load, hence the effect of noise on their concentration.

The level of awareness of effect of noise pollution on incidence of cardiovascular diseases which is the leading cause of death is significantly low. Only $5.5 \%$ of the respondents were aware of its health effect on cardiovascular system. This is in line with the findings of Awosusi et al where the respondents' awareness of its cardiovascular effects was below the mean score of 1.5. The study of Awosusi et al was among the people of Ado Ekiti Metropolis comprising people of varying educational status. This thus shows that educational status thus not has effect on the awareness of the association of noise pollution on the cardiovascular system.

There is low level of awareness of legislation against community noise pollution. The low level of awareness of country law against noise pollution points to the facts that it is being poorly implemented i.e. there is poor enforcement of the law. With most of the laws being promulgated during military era with little or no community participation. This could be partly responsible for low level of awareness.

In conclusion, noise pollution is a problem both on our campuses and their hosting communities. The high level of awareness does not correlate with reduction in exposure as majority of the respondents $(88.8 \%)$ get exposed among whom $62.4 \%$ of them getting exposed daily. Despite the moderate level of awareness, more still need to be done to check its rising prevalence.

Recommendation

There is need for more enlightenment campaign to improve awareness on the adverse effect of noise pollution. There should also be enlightenment on measures to reduce noise pollution exposure both at individual and community level.

There should be engagement of operators of public places that produce noise e.g. churches, mosques, club houses and others

The government should put in more action to ensure implementation of existing laws against noise pollution, improvement of power supply to reduce usage of generators. There should also be construction of better road network to ease traffic congestion. 


\section{References}

[1.] Aluko, E., \& Nna, V. (2015). Impact of noise on human cardiovascular system. International Journal of Tropical Disease and health, 6(2), 35- 43.

[2.] Ana, R., Shendel, D., Brown, G., \& Sridar, M. (2009). Assessment of noise and associated health impacts at selected secondary schools in Ibadan, Nigeria. Journal of Environmental and Public Health, 2009.

[3.] Awosusi, A. O., \& Akindutire, I. O. (2014). Percieved health effect of environmental noise pollution on the inhabitant of Ado Ekiti metropolis, Ekiti State Nigeria. Journal of Biology Agriculture and Healthcare, 4(26), 106- 113 .

[4.] Bulunuz, N. (2014). Noise Pollution in Turkish elementary schools: Evaluation of noise pollution awareness and sensitivity tranning. International Journal of Environmental and science Education, 9, 215- 234.

[5.] Committee, S. P. W. Noise pollution and abatement act of 1972. (S. Rep. No. 1160).

[6.] Essandoh, P. K., Armah, F. A., Afrifa, E. K., \& Pappoe, A. N. (2011). Determination of ambient noise levels and perception of residents in Halls at the University of Cape Coast, Ghana. Environment and Natural Resources Research, 1(1), 181- 188.

[7.] Farzana, S. Z., Nuri, A. H., Biswas, B., \& Das, A. (2014). A study on noise pollution of stone crusher machine at Jaflong, Sylhet Paper presented at the Proceedings of 5th International Conference on Environmental Aspect of Bangladesh, Bangladesh

[8.] Lisa, G., \& Louis, H. (2007). Noise Pollution: A Mordern Plague. Southern Medical Journal, 100, $287-$ 294.

[9.] Onuigbo, L. N., Onuoha, J. C., \& Ugwuanyi, L. T. (2013). Noise induced hearing loss among social studies education students in tertiary institutions in Enugu State, Nigeria: Awareness and safety issues. International Journal of Current Research.

[10.] Osun, S. o. (2014). The Omoluabis Retrieved 15/10/15, 2015, from www.osunstate.gov.ng/aboutosun/thepeople

[11.] Park, K. (2009). Preventive and Social Medicine. India: M/s Banarsidas Bhanot.

[12.] Shield, B. M., \& Dockrell, J. E. (2003). The effect of noise on children at school: A review. Journal of Building Acoustics, 10(2), 97- 106.

[13.] Understanding noise pollution. Retrieved 09/10/2015, from http://www.conserve-energyfuture.com/causeand-effect-of-noise-pollution.php 